Supplement of E\&G Quaternary Sci. J., 70, 53-71, 2021

https://doi.org/10.5194/egqsj-70-53-2021-supplement

(c) Author(s) 2021. This work is distributed under

the Creative Commons Attribution 4.0 License.

(c) (1)

Supplement of

\title{
A comparison of polymineral and $K$-feldspar post-infrared infrared stimulated luminescence ages of loess from Franconia, southern Germany
}

Neda Rahimzadeh et al.

Correspondence to: Neda Rahimzadeh (neda.rahimzadeh@leibniz-liag.de)

The copyright of individual parts of the supplement might differ from the CC BY 4.0 License. 


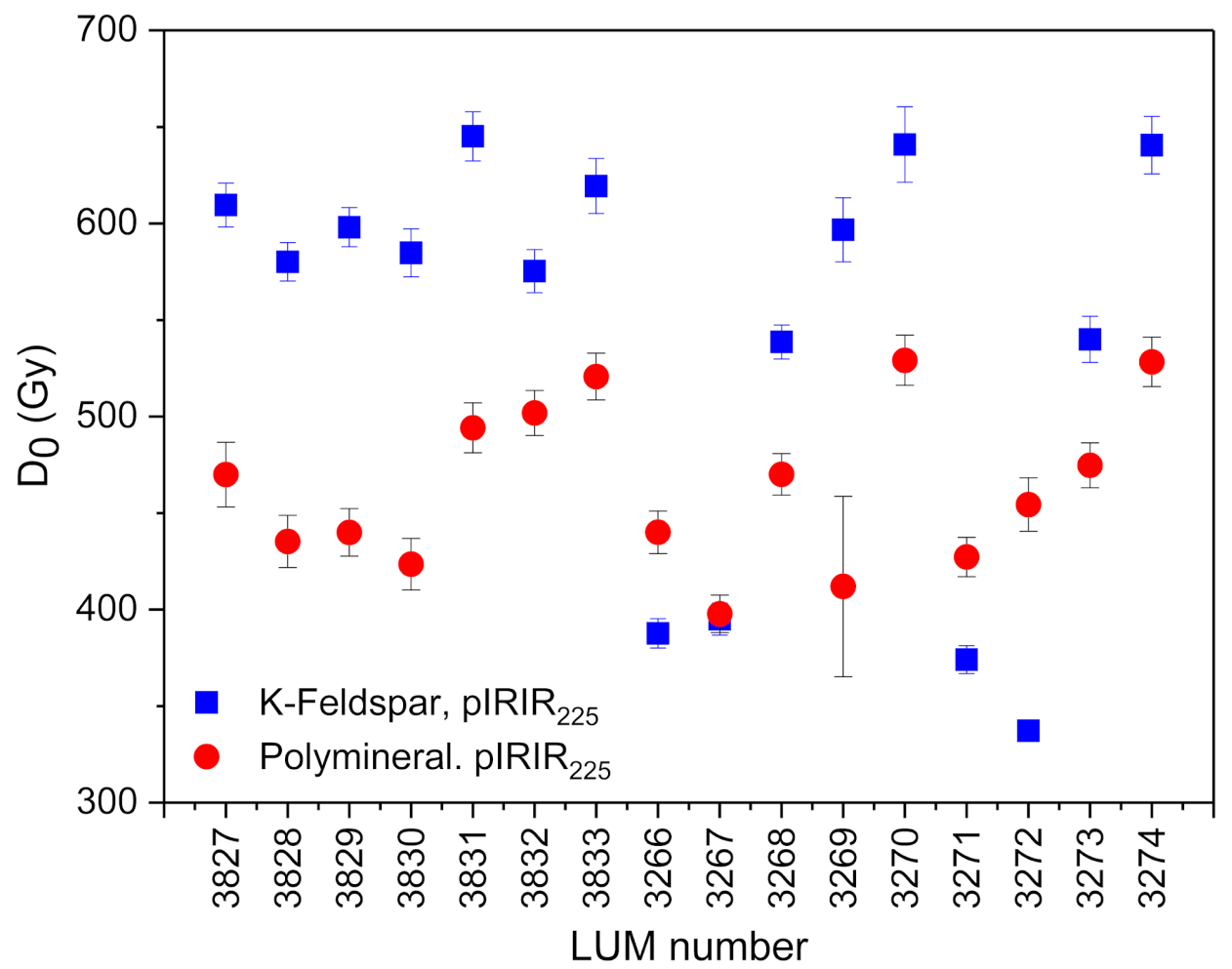

Figure S1. $D_{0}$ comparison for pIRIR 225 signal for the fine (in red) and coarse (in blue) fractions 